\title{
Using Blade Element Momentum Theory to Predict the Effect of Wave-Current Interactions on the Performance of Tidal Stream Turbines
}

\author{
Song Fu, Stephanie Ordonez-Sanchez, Rodrigo Martinez, Matthew Allmark, Cameron Johnstone, Tim \\ O'Doherty
}

\begin{abstract}
The non-uniformity and dynamics of the environment tidal stream turbines need to operate within will significantly influence the durability and reliability of tidal energy systems. The loadings on the turbine will increase substantially when the turbine is deployed in high magnitude waves with non-uniform tidal currents. The limitations of numerical solutions will be understood when the outcomes are verified with empirical data from system operations. In this paper, a Blade Element Momentum model is used to predict and compare the performance of a scaled turbine within a flume and a tow tank. Firstly, the numerical and experimental work is analysed for a turbine operating at flow speeds of $0.5 \mathrm{~m} / \mathrm{s}$ and $1.0 \mathrm{~m} / \mathrm{s}$, wave heights of $0.2 \mathrm{~m}$ and $0.4 \mathrm{~m}$ and wave periods of $1.5 \mathrm{~s}$ and $1.7 \mathrm{~s}$. Good agreement between the model and the experimental work was observed. However, in low TSRs the model tends to under predict the thrust, and the variation between the maximum and minimum values obtained within the experiments. Secondly, a turbine operating at flow speeds of $1.0 \mathrm{~m} / \mathrm{s}$ and 4 different inflow profiles is analysed, where the wave heights for these cases were $0.09 \mathrm{~m}$ and $0.19 \mathrm{~m}$ and with wave periods of $2 \mathrm{~s}$ and $1.43 \mathrm{~s}$. In this evaluation, the model tends to over predict the values of $C_{T}$ and $C_{P}$ when compared to those calculated from the experimental data. However, when investigating the values used to calculating both the thrust and torque coefficients, there is better agreement with these, which means the methodology used to determine these coefficients with inflow profiles should be revised.
\end{abstract}

\footnotetext{
Manuscript received 3 March, 2021; revised 12 April, 2021; accepted 13 April, 2021; published 21 May, 2021.

This is an open access article distributed under the terms of the Creative Commons Attribution 4.0 licence (CC BY http://creativecommons.org/licenses/by/4.0/). unrestricted use (including commercial), distribution and reproduction is permitted provided that credit is given to the original author(s) of the work, including a URI or hyperlink to the work, this public license and a copyright notice.

This article has been subject to single-blind peer review by a minimum of two reviewers. The authors would like to recognise the support of the UK EPSRC in funding some of the research as part of EPSRC Grant No. EP/N020782/1.

Song $\mathrm{Fu}$ is with Energy Systems Research Unit, University of Strathclyde Glasgow, G1 1XJ, United Kingdom (e-mail: song.fu@strath.ac.uk)
}

Keywords - Tidal Turbine, Blade Element Momentum Theory, Wave-Current Interactions, Inflow profile, Experiments, Loading.

\section{INTRODUCTION}

$\mathrm{T}$ HE evolution of the marine renewable energy industry is expanding rapidly with new developments around the globe. Atlantis Ltd has started to explore the use of tidal stream energy in Japan [1] while Swedish company, Seabased, has prepared to provide renewable energy to Sri Lanka, starting with an initial installation to power a fish farm [2]. While this relates to good progress in the marine energy industry development, there is still many challenges to be tackled before the technology may be considered durable and reliable in commercial operations.

One of the main contributors relating to the potential failure of offshore marine energy converters, is the complex and variable nature of the resource. The effects of turbulence have been assessed by a number of authors experimentally and numerically. However, waves and wave-current interactions also affect the durability and reliability of TST's and are the main focus of this paper.

The interactions of wave and currents in TSTS have been studied both numerically and experimentally by several researchers. Authors. [3] and [4] explored the use of Blade Element Momentum Theory (BEMT) and Computational Fluid Dynamic techniques (CFD), respectively, to investigate the effects of oscillatory motion of waves on TST rotor and drivetrain performance. They reported the

Stephanie Ordonez-Sanchez is with Energy Systems Research Unit, University of Strathclyde Glasgow, G1 1XJ, United Kingdom (e-mail: s.ordonez@strath.ac.uk).

Rodrigo Martinez is with Energy Systems Research Unit, University of Strathclyde Glasgow, G1 1XJ, United Kingdom (e-mail: r.martinez@strath.ac.uk).

Matthew Allmark is with School of Engineering, Cardiff University Cardiff CF24 3AA, United Kingdom (e-mail: AllmarkMI1@cardiff.ac.uk).

Cameron Johnstone is with Energy Systems Research Unit, University of Strathclyde Glasgow, G1 1XJ, United Kingdom (e-mail: cameron.johnstone@strath.ac.uk).

Tim O'Doherty is with School of Engineering, Cardiff University Cardiff CF24 3AA, United Kingdom (e-mail: Odoherty@cardiff.ac.uk).

Digital Object Identifier https://doi.org/10.36688/imej.4.25-36 
combination of wave-current interactions introduces nonuniform bending moments simultaneously on the turbine blades, which translate to eccentric loading of drivetrain components, creating damaging effects. While the work undertaken by [3] and [4] enables the investigation of wave-current interactions with few changes of wave and current parameters, the numerical model predictions need to be empirically verified to understand potential limitations within the numerical methods employed.

Experimental research related to wave-current interactions with TSTs have been undertaken by several authors, e.g., [5] - [6]. In each of the testing campaigns, the authors have focused on investigating different aspects of the systems performance. For example, a $0.4 \mathrm{~m}$ diameter turbine is used in [5] to investigate the effects that a variety of wave periods and heights had on the turbine. The results presented in this work provided an initial understanding of the detrimental effects that wave-current interactions can have in TSTs by comparing out of plane bending moments occurring on the rotor using both numerical and experimental work. However, the work presented there is somewhat unclear on the specific outcomes for each of the testing conditions. The effects of wave-current interactions on a $0.9 \mathrm{~m}$ diameter turbine by varying two wave periods and two wave heights were investigated in [7]. This established that the average values for torque and thrust remained similar to a base case without wave influences. However, the fluctuations arising from the wave-current interactions on the loading of the rotor were in the region of two or three times greater in magnitude. This investigation was insightful but was restricted to 'small' wave heights of $0.2 \mathrm{~m}$ and wave frequencies between 0.5 and 0.7 and low flow velocities of $0.6 \mathrm{~m} / \mathrm{s}$. Experimental analysis on wave current interactions on a turbine of $0.5 \mathrm{~m}$ rotor diameter is undertaken in [8] by using a single flow speed of $0.5 \mathrm{~m} / \mathrm{s}$ and two waveforms.

The experiments were carried out in a flume facility and it was found that average values of power and thrust remained similar for the wave and no wave conditions. The fluctuations of power and thrust were shown to be significantly higher, using standard deviation values; however, it was difficult to quantify the actual peak variations of the time or frequency domain signals. An experimental campaign is undertaken in [6] where temporal variations of loadings were analysed on a scaled turbine of $0.5 \mathrm{~m}$ diameter operating under larger amplitude waves and tow speed of $1.0 \mathrm{~m} / \mathrm{s}$. Later, the same turbine was tested at a flume facility aiming to replicate the tests done at the tow facility; however, due to the limitations of the facility, only the $0.5 \mathrm{~m} / \mathrm{s}$ tests were carried out. The information from these testing campaigns will be used to verify the numerical model presented in this paper.

As can be seen from the literature, the disparity of the experimental work is influenced by different factors, e.g. the testing facility, the turbine design, the costs associated with practicalities of testing, etc. But the average $C_{T}$ and $C_{P}$ are not obviously influenced by the waves due to the fluctuation of the waves. This paper aims to compare and validate an in-house BEMT model developed to quantify loading with combined waves and current based on the empirical test data described previously. This means the investigation considers a variety of flow speeds in two different facilities at similar wave conditions, where possible.

\section{Methodology}

\section{A. Blade Element Momentum Theory}

Blade Element Momentum Theory (BEMT) is widely used in the renewable energy sector. It was originally developed and has been used extensively to model the performance of wind turbines; and has extended and applied to the marine energy industry. The theory is based on the conservation of axial and angular momentum where power and thrust can be inferred. The annular section representing the turbine rotor is then split into a number of elements in the radial direction. Thus, each of the elements is analysed independently to calculate normal and tangential forces using aerodynamic coefficients as complementary information to solve the set of equations. This means that depending on the blade geometry and the inflow characteristics, the lift $(\mathrm{Cl})$ and drag $(\mathrm{Cd})$ coefficients which are related to the forces acting on the blade sections will change. Therefore, when estimating power and thrust using BEMT, the $\mathrm{Cl}$ and $\mathrm{Cd}$ parameters utilised can have a high influence in the outcomes.

$\mathrm{Cl}$ and $\mathrm{Cd}$ coefficients can be obtained from several sources. A database of a large number of aerofoil coordinates and their performance at diverse Reynolds numbers can be found in [9]. If the required parameters are not covered by the available literature, the coefficients can be calculated using numerical models, e.g, Xfoil, Profil 07, Javafoil. For this investigation, two different Reynolds numbers (100000 and 200000) were used for the calculation of power and thrust coefficients for a Wortmann FX 63-137 aerofoil.

The BEMT model used in this investigation was developed at Strathclyde University [3]. Prandtl tip and hub loss correction factors were utilised in the BEMT calculations. Buhl correction was implemented to account for axial induction factors higher than the theoretical upper limits and the Viterna-Corrigan method was applied to estimate high flow angles during post stall values. A similar approach was undertaken in [10]. Buhl correction was applied to address the high induction factor correction [11]. Morison equations which consider the drag and inertial forces on a submerged body in oscillatory flows is applied as a correction.

Two inflow conditions are discussed in this paper, uniform inflow and non-uniform inflow. For uniform inflow conditions, the influence of waves was taken into account by using the coupled wave-current model where the current was a constant and the wave was considered as third order stokes wave. For conditions with inflow 
profiles, the wave-current model is established by using a current model based on the inflow profiles coupled with the second order stokes wave model, and the horizontal wave particle velocity was cancelled because it has already been added in the inflow profile. To validate the BEMT model results for the uniform and non-uniform flows, the results from two test campaigns were utilised and these are also briefly described in the following sections.

\section{B. Uniform inflow}

A scaled horizontal axis turbine of $0.5 \mathrm{~m}$ diameter was employed in the experimental campaigns and is attributed within the BEMT model. The turbine rotor is comprised of three rotor blades with a Wortmann FX 63-137 aerofoil profile. The rotor has a radius of $0.25 \mathrm{~m}$, with a hub radius of $0.05 \mathrm{~m}$. The optimum pitch for this design is 6 degrees. This pitch setting was set by adjusting the blade root to the hub with a grub screw. Further details of the blade geometry, including the chord length and twist can be found in [12].

Flow speeds of $0.5 \mathrm{~m} / \mathrm{s}$ and $1.0 \mathrm{~m} / \mathrm{s}$ were tested and simulated based on the experimental campaigns undertaken at two facilities, a flume and a tow tank. The carriage speed used in the tow tank and the current speed used in the flume are both referred to here as flow speeds. The current only conditions is considered as Case CO1 and CO2. Three additional cases are also considered using combinations of flow speeds, wave heights and wave periods. Case WF1 refers to a flow speed of $0.5 \mathrm{~m} / \mathrm{s}$ with a wave height of $0.4 \mathrm{~m}$ and an apparent wave period of $1.71 \mathrm{~s}$. As these tests were undertaken in a tow tank, the apparent period considered the movement of the tow carriage into the waves generated at the far end of the facility, as proposed in [13]. Therefore, it simulates as if the current and the waves travel in the same direction. WF2 attempted to replicate the same wave conditions in a flume tank. Due to the limitations of the facility, a wave height of nearly 0.2 $\mathrm{m}$ and a period of $1.71 \mathrm{~s}$ was used in the experiments. Case WF3 relates to the wave-current experiments that were undertaken at the tow facility at $1.0 \mathrm{~m} / \mathrm{s}$. The wave height

TABLE II

TESTING PROGRAMME FOR INFLOW PROFILES

\begin{tabular}{|c|c|c|c|c|c|c|c|}
\hline Cases & $\begin{array}{c}\text { Flow Speed } \\
(\mathrm{m} / \mathrm{s})\end{array}$ & $\begin{array}{l}\text { Wave height } \\
\text { (m) }\end{array}$ & $\begin{array}{c}\text { Wave period } \\
\text { or apparent } \\
\text { wave period } \\
\text { (s) }\end{array}$ & $\begin{array}{c}\text { Full scale } \\
\text { wave height } \\
(\mathrm{m})\end{array}$ & $\begin{array}{c}\text { Full scale } \\
\text { wave period } \\
\text { or apparent } \\
\text { wave period } \\
\text { (s) }\end{array}$ & $\begin{array}{l}\text { Turbine } \\
\text { Installed }\end{array}$ & $\begin{array}{l}\text { Type of } \\
\text { facility }\end{array}$ \\
\hline RW1 & Profile (a) & 0.19 & 1.43 & 3.8 & 6.67 & Yes & Flume \\
\hline NRW1 & Profile (b) & 0.19 & 1.43 & 3.8 & 6.67 & No & Flume \\
\hline RW2 & Profile (c) & 0.09 & 2 & 1.8 & 9.01 & Yes & Flume \\
\hline NRW2 & Profile (d) & 0.09 & 2 & 1.8 & 9.01 & No & Flume \\
\hline
\end{tabular}

\section{Vertical velocity profile}

To get a better understanding of the vertical velocity profile in plane and up-stream of the rotor installation, for this current speed was set to $0.4 \mathrm{~m}$ and an apparent wave period of $1.5 \mathrm{~s}$.

The cases simulated using BEMT and explored in the testing campaigns are summarised in Table I.

TABLE I

TESTING PROGRAMME

\begin{tabular}{lllll}
\hline Cases & $\begin{array}{l}\text { Flow } \\
\text { Speed } \\
(\mathrm{m} / \mathrm{s})\end{array}$ & $\begin{array}{l}\text { Wave } \\
\text { height }(\mathrm{m})\end{array}$ & $\begin{array}{l}\text { Wave } \\
\text { Period or } \\
\text { apparent } \\
\text { wave } \\
\text { period }(\mathrm{s})\end{array}$ & $\begin{array}{l}\text { Type of } \\
\text { facility }\end{array}$ \\
\hline CO1 & 0.5 & 0 & 0 & $\begin{array}{l}\text { Flume and } \\
\text { Tow }\end{array}$ \\
CO2 & 1 & 0 & 0 & Flume and \\
WF1 & 0.5 & 0.4 & 1.71 & $\begin{array}{l}\text { Tow } \\
\text { Tow } \\
\text { WF2 }\end{array}$ \\
WF3 & 0.5 & 0.2 & 1.71 & Tow \\
\hline
\end{tabular}

\section{Non-uniform inflow}

A scaled horizontal axis turbine of $0.9 \mathrm{~m}$ diameter was employed both in the experimental and the BEMT. The rotor blades are $0.385 \mathrm{~m}$ in length and were designed using a Wortmann FX 63-137 aerofoil profile, with a hub radius of $0.065 \mathrm{~m}$.

Non-uniform inflows were tested and measured during the experiments in the Ifremer flume tank. The velocity components in the $\mathrm{X}, \mathrm{Y}, \mathrm{Z}$ axis were measured incrementally in front of the rotor plane form $0.55 \mathrm{~m}$ to $1.45 \mathrm{~m}$ below the water surface during the two wave conditions. The regular wave 1 condition (RW1) had a wave height of $0.19 \mathrm{~m}$ with a wave period of $1.43 \mathrm{~s}$. Case regular wave 2 (RW2) was a condition with $0.09 \mathrm{~m}$ wave height and $2 \mathrm{~s}$ wave period. In addition, the inflow profiles were measured for both wave conditions as NRW1 and NRW2 while the turbine was removed from the flume tank. All cases simulated in BEMT are given in Table II.

The cases with and without the turbine were compared to investigate the turbine influence on the inflow and which inflow profiles the outputs of BEMT match the experiment appropriately. 
reported this was characterised for a turbine centre hub height located $1 \mathrm{~m}$ below the undisturbed water surface level. The resulting velocity profile variations for the cases investigated are shown in Figures 1 and 2.

The vertical inflow profiles are non-uniform due to flow velocities near and sub-surface being impeded by the submergence of the wave makers. Therefore, the inflow velocity deeper in the water column shows a trend of being higher than the near surface velocities.

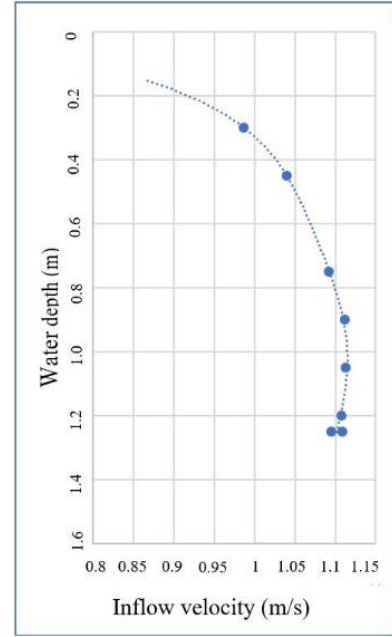

(a)

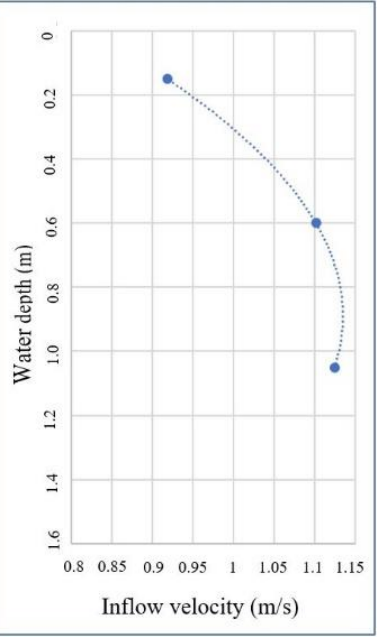

(b)
Figure 1. Inflow profiles for RW1 amd NRW1. (a) is RW1 as the profile with turbine installed, (b) is NRW1 as the profile without turbine installed

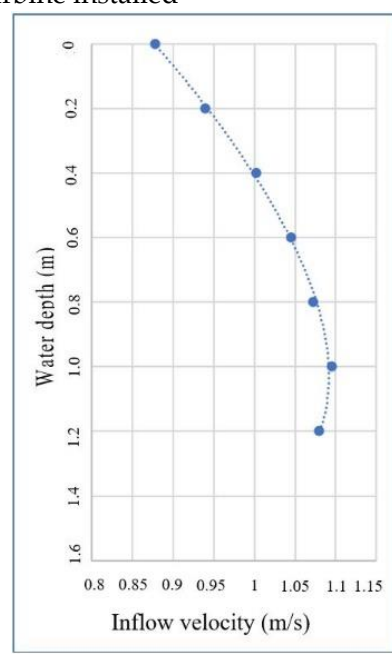

(c)

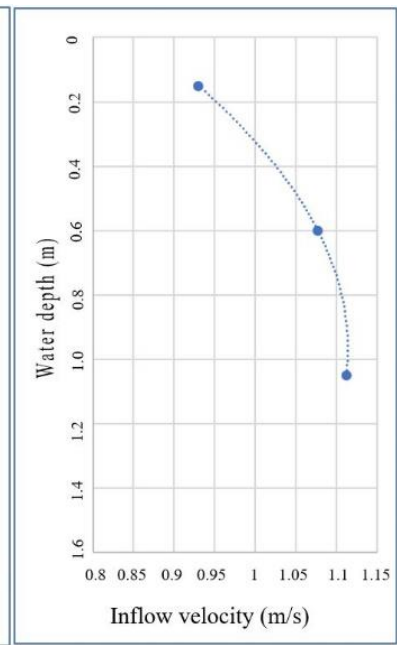

(d)
Figure 2. Inflow profiles for RW2 and NRW2. (c) is RW2 as the profile with turbine installed, (d) is NRW2 as the profile without turbine installedExecution of the experimental Campaigns

Within this section, the test program and the experimental setup is described. For the experimental campaign, a $0.5 \mathrm{~m}$ diameter turbine designed by Cardiff University was used to validate the numerical model described in the previous section. The diameter of the turbine is marginally smaller when compared to other devices tested, which were in the range of 0.7 to $1 \mathrm{~m}$ in diameter. It has previously been reported [14] that it is possible to achieve Reynolds independency for the rotor at flow velocities $>0.9 \mathrm{~m} / \mathrm{s}$.

Experiments were undertaken within two facilities, a tow tank located at CNR-INSEAN laboratory in Rome,
Italy and a circulating flume tank located at Ifremer research centre at Boulogne Sur Mer, France. Table 3 shows the characteristics of the facilities.

TABLE III

DETAILS OF THE TOW AND FLUME TANKS

\begin{tabular}{ccc}
\hline Facilities & CNR-INSEAN & IFREMER Centre \\
\hline $\begin{array}{c}\text { Facility } \\
\text { dimensions } \\
\text { Flow velocities } \\
\text { tested } \\
\text { Turbulence } \\
\text { intensity }\end{array}$ & $220 \mathrm{~m} \times 9 \mathrm{~m} \times 3.5 \mathrm{~m}$ & $18 \mathrm{~m} \times 4 \mathrm{~m} \times 2 \mathrm{~m}$ \\
Blockage ratio & $0.5 \mathrm{~m} / \mathrm{s}$ & 0.5 and $1.0 \mathrm{~m} / \mathrm{s}$ \\
\hline
\end{tabular}

\section{E. Experimental setup, turbine design and instrumentation}

The turbine was secured using a vertical stanchion in both facilities $1.0 \mathrm{~m}$ below the undisturbed water surface level, as observed in Figure 4.

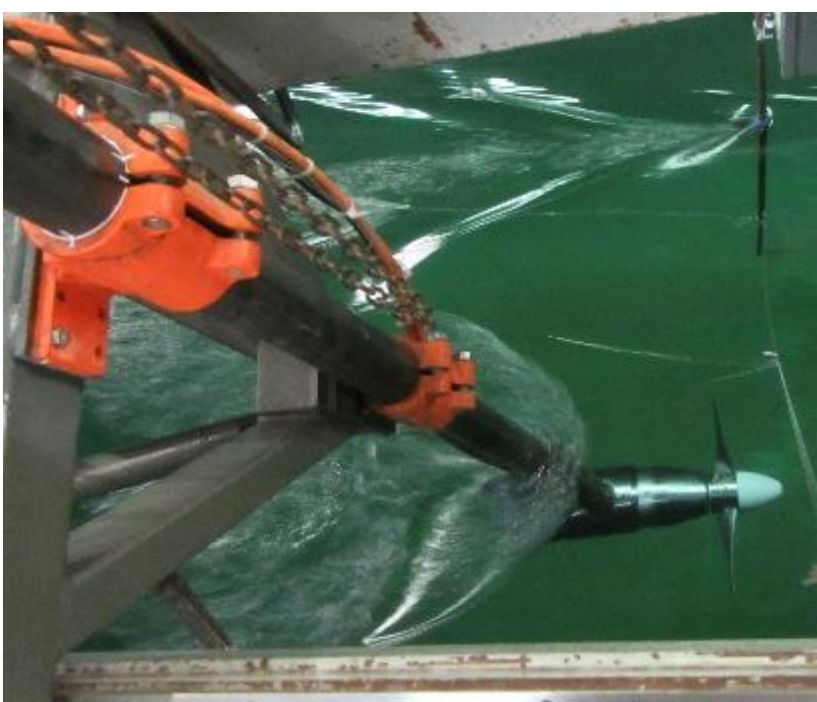

Figure 3. Turbine installed at the tow tank at CNR-INSEAN

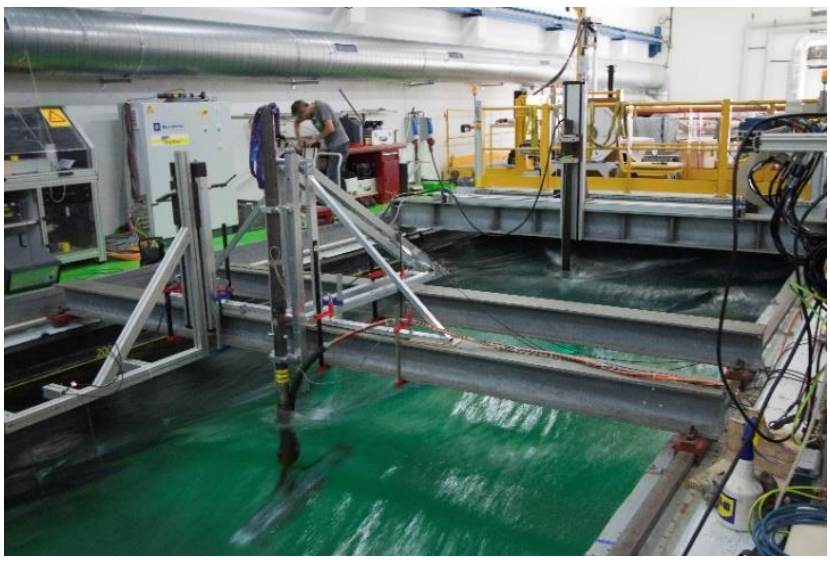

Figure 4 . Turbine installed at the flume facility at Ifremer.

For the tow tank tests, the flow velocity and the wave height and period was monitored during each of the tests using a pitot tube and a wave probe installed next to the 
turbine at the same height as the rotor hub $(1.0 \mathrm{~m}$ below the free surface). For the flume experiments at Ifremer, a laser Doppler velocimeter was installed 7.2 diameters (D) upstream the rotor at $1.0 \mathrm{~m}$ below the free surface. Three resistance wave probes were installed next to the turbine to measure the wave heights during the operation of the turbine. More information of both testing campaigns can be found in [6] and [15], including uncertainty analysis.

For both testing campaigns, National Instruments LabVIEW was used as the data acquisition system.

\section{F. Data Processing}

For comparative purposes, the rotor torque, thrust, and rotational speeds were averaged over time for each test. Non-dimensional values of power and thrust for the experimental and BEMT were also used to analyse the data. These are based on the following formulas:

$$
\begin{aligned}
C_{P} & =\frac{P}{0.5 \rho A V^{3}} \\
C_{T} & =\frac{F}{0.5 \rho A V^{2}}
\end{aligned}
$$

where $\mathrm{P}$ is average power in Watts, and $\mathrm{F}$ is the average thrust in Newton (N). A is the swept area of the rotor in meters, and $\mathrm{V}$ denotes the unidirectional flow velocity $(\mathrm{m} / \mathrm{s})$. In uniform inflow tests, this relates to the average flow measured at the turbine hub height in the flume and the carriage velocity when undertaking tow tank tests. In non-uniform inflow tests, 5 measure points were taken at top, bottom, left, right and centre of the swept rotor area in the experiment, then $\mathrm{V}$ was defined as the mean value of their measurement results. However, this mean value resulted in some variances which will be discussed later.

The average $C_{p}$ and $C_{T}$ are plotted against the average tip speed ratio (TSR) values for each test run. TSR denotes the ratio between the blade tip speed and the flow velocity $(\mathrm{V})$ :

$$
\mathrm{TSR}=\frac{\Omega r}{V}
$$

where $\Omega$ rotor speed in $\mathrm{rad} / \mathrm{s}$ and $\mathrm{r}$ is the radius of the turbine.

The influence of blockage is considered for the nonuniform tests. The method adopted to calculate the power and thrust coefficient with blockage correction is presented by Bahaj et. al. [16].

\section{RESULTS AND DISCUSSION}

This section presents the comparative results obtained from BEMT and the experimental campaigns. The first section includes average values of power and thrust shown in its non-dimensional form using equations 1-3. The second section shows selected cases where the non- uniform inflows are compared between the analytical and experimental values.

\section{G. Power and Thrust Coefficients for Uniform flows}

Figures 5 and 6 show the comparison of the average $C_{T}$ values obtained for the experiment and BEMT. As mentioned earlier, thrust measurements of the rotor were acquired during the testing campaign undertaken at Ifremer and thus, only for flow velocities of $0.5 \mathrm{~m} / \mathrm{s}$. For the current only condition, the match between the experimental values and BEMT follows the same trend for most of the $\mathrm{C}_{\text {T-TSR }}$ curve (Figure 7 ). With TSR values $>4$ the discrepancy between BEMT and experiment increases, where the experimental values tend to increase in value with TSR and the analytical model predicts an opposite trend.

In Figure 6, a large discrepancy between the experiment and the analytical model can be observed. For all the TSR cases, the analytical values are about $18 \%$ higher than the experimental data. This can somewhat be expected as the power predictions were also higher (by approximately $40 \%$ in the wave cases) when power was quantified using the BEMT model.

There are a couple of reasons which may explain the differences between the thrust values of the experiment and the BEMT model. As mentioned in Section II-B, thrust was measured in the experiment by incorporating a full bridge load cell on the stanchion used to support the turbine in the flume. Therefore, instead of measuring actual thrust, the real data acquired was a bending moment rather than the actual thrust developed by the turbine. This can be corrected by acquiring information of the setting used in the experiment under the influence of the flow variations, i.e. current only and wave and current conditions when the turbine is not operating. Moreover, the calibration of the stanchion should be done using the exact configuration of the experiment, i.e. the calibration should be done in situ. Another option is to "dry" calibrate the stanchion using a similar configuration as the one used in the laboratory, in this case, by mounting vertically the stanchion and applying a variety of loadings in the horizontal direction, to simulate the loads created by the turbine. Due to laboratory access and time constrains, the calibration of the stanchion in these experiments was done horizontally and the loading was applied vertically, which may give an insight of the voltage vs loading trend; however, the outcomes may translate to a larger experiment uncertainty.

Another factor that may influence the thrust measurement on the stanchion is related to the shear flows observed in the flume. It has been observed in [15] that the variability of the flows in that facility is highly affected by the use of surface mounted wave makers on the flume facility. 


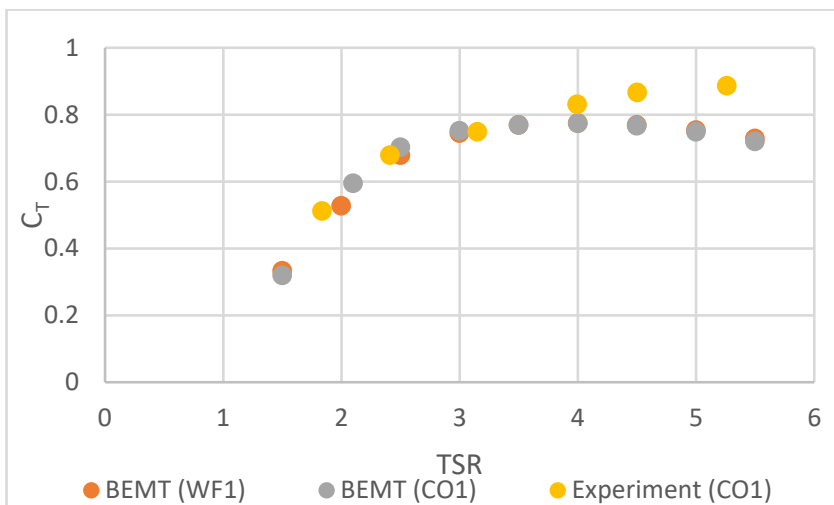

Figure 5. С с comparison between BEMT and experiment for the 0.5 $\mathrm{m} / \mathrm{s}$ case when the turbine operates under current only conditions.

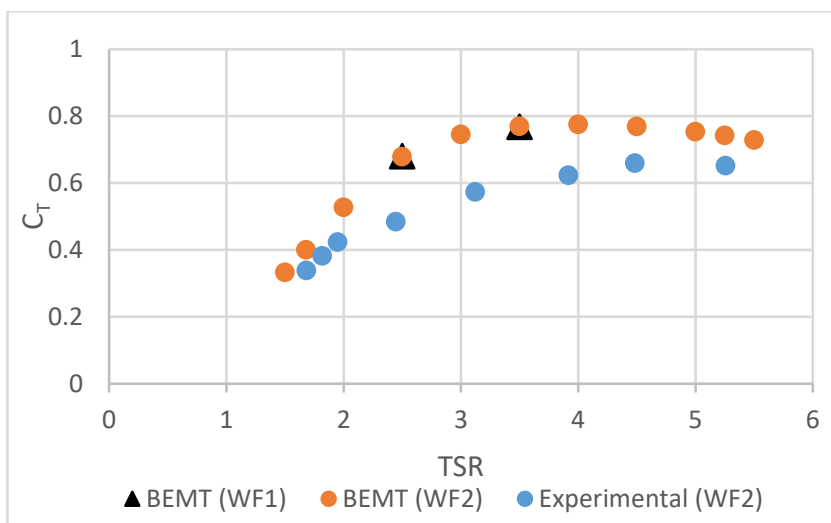

Figure 6. С $\mathrm{C}_{\mathrm{T}}$ comparison between BEMT and experiments undertaken at Ifremer for the $0.5 \mathrm{~m} / \mathrm{s}$ case when the turbine operated under wave-current interactions with a wave height of approximately $0.2 \mathrm{~m}$ and a wave period of $1.7 \mathrm{~s}$.

Figures 7-9 show the comparisons of $\mathrm{C}_{\mathrm{P}}$ and $\mathrm{C}_{\mathrm{T}}$ for the $1.0 \mathrm{~m} / \mathrm{s}$ cases. It can be observed a good agreement on the power coefficient between BEMT and the experimental for both current only and wave cases and for most of the TSR values. The major discrepancy observed in the average values of $C_{P}$ for the experiment and the BEMT was approximately $7 \%$ for a TSR $=2.3$; however, the other cases presented disparities of approximately $2 \%$.

For the $\mathrm{C}_{\mathrm{T}}$ comparisons, limited data was available from the testing campaigns to corroborate the simulations undertaken in BEMT. This is one aspect that will be further investigated in the future. However, for comparisons purposes, both average values of $\mathrm{C}_{\mathrm{T}}$ for simulations done with and without waves are presented in Figure 9. It can be observed that the models predict similar average values for both cases, as was to be expected, especially since at this point shear flows are not considered in the calculations.

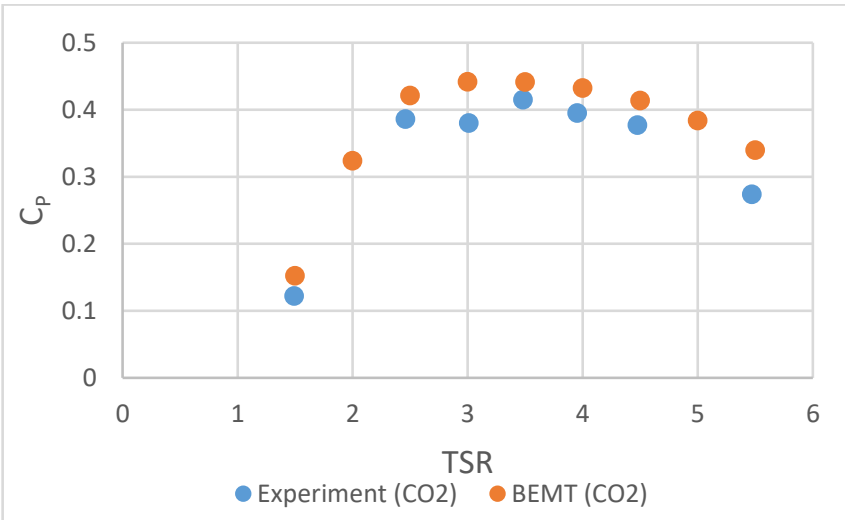

Figure 7. СР comparison between BEMT and experiments undertaken at Insean for the $1.0 \mathrm{~m} / \mathrm{s}$ case when the turbine operates under current only conditions.

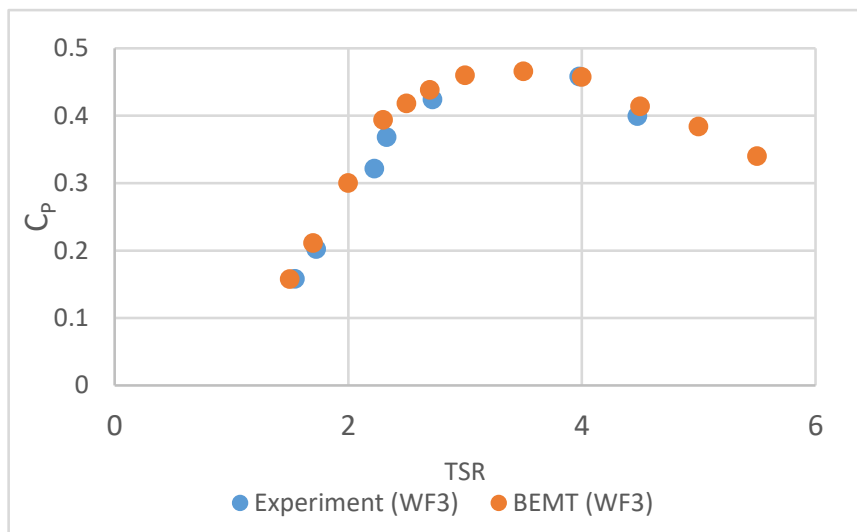

Figure 8. С $\mathrm{CP}_{\mathrm{f}}$ comparison between BEMT and experiments undertaken at Insean for the $1.0 \mathrm{~m} / \mathrm{s}$ case when the turbine operated under wave-current interactions with a wave height of approximately $0.4 \mathrm{~m}$ and an apparent wave period of $1.5 \mathrm{~s}$

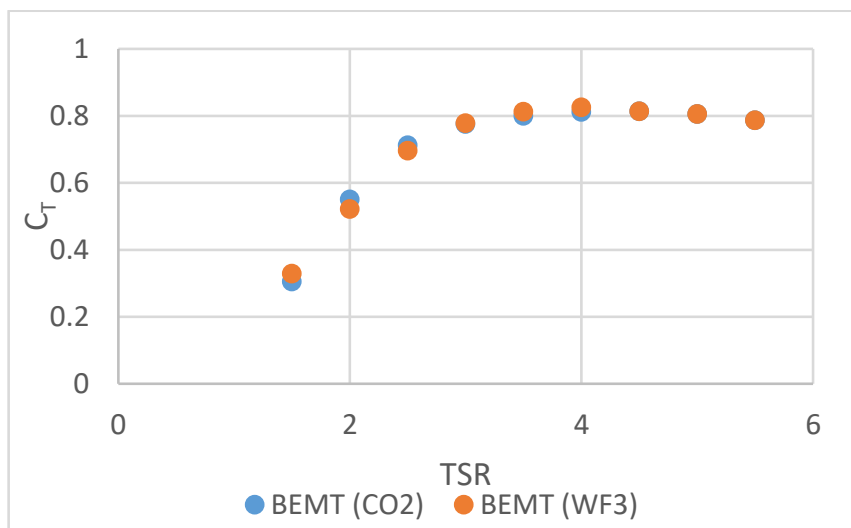

Figure 9. С T comparison between BEMT calculations for the $1.0 \mathrm{~m} / \mathrm{s}$ case during "current only" conditions and when the turbine operates under wave-current interactions with a wave height of approximately $0.4 \mathrm{~m}$ and an apparent wave period of $1.5 \mathrm{~s}$

\section{POWER COEFFICIENTS AND LOADS FOR NON- UNIFORM FLOWS}




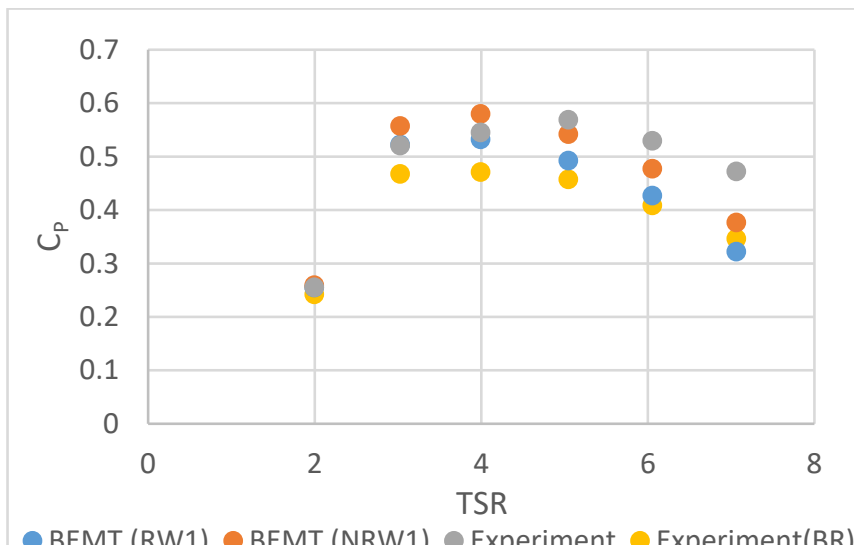

BEMT (RW1) BEMT (NRW1) Experiment Experiment(BR)

Figure 10. С $\mathrm{C}_{\mathrm{P}}$ comparison between BEMT calculations and experimental data for the inflow profiles with and without a turbine when the turbine operates under wave-current interactions with a wave height of approximately $0.19 \mathrm{~m}$ and an apparent wave period of $0.7 \mathrm{~s}$.

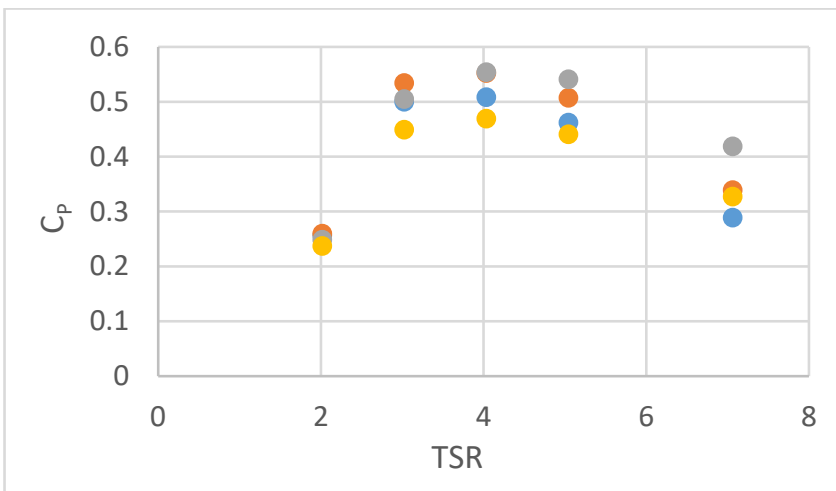

- BEMT (RW2) B BEMT (NRW2) Experiment Experiment(BR)

Figure 11. $\mathrm{CP}_{\mathrm{P}}$ comparison between BEMT calculations and experimental data for the inflow profiles with and without a turbine when the turbine operates under wave-current interactions with a wave height of approximately $0.09 \mathrm{~m}$ and an apparent wave period of $0.5 \mathrm{~s}$.

Figures 10-11 demonstrates the comparisons of $C_{P}$ for the BEMT model with Experimental data for two inflow cases. It can be observed that the experimental data shows good agreement with BEMT in RW1 condition from TSR 2 to 4 and RW2 condition from TSR 2 to 3, before the Experimental and BEMT data begin to diverge. At a TSR of 7 the differences between the Experimental data and the BEMT predictions becomes approximately $20 \%$ for all test conditions. For the two inflow profiles applied, this shows a difference in $C_{P}$ from TSR 3 to 7 where the inflow profile associated with a turbine in both wave condition being generally $9 \%$ less than an associated inflow profile without a turbine present.

The application of a blockage ration (BR) within the experimental data improves the miss match to approximately $11 \%$ for an inflow profile representative of a turbine, and $16 \%$ for an inflow profile representative without a turbine when compared with the BEMT results for two inflow profiles in RW1 cases at TSR 3. These differences increase to $14 \%$ and $17 \%$, respectively at a TSR 4. This difference starts to decrease from TSR 5 to TSR 7, with the final differences becoming $6 \%$ and $8 \%$. Similar trends are also evident in the RW2 conditions where these discrepancies increase to $13 \%$ and $20 \%$ at TSR 3 , then drops slowly to $12 \%$ and $3 \%$ at TSR 7 .

It can be observed that introducing correction for blockage has a significant effect when comparing the BEMT results with the experimental data. These differences are reduced with the application of blockage correction, especially when comparing the performance for operations in a RW2 condition.

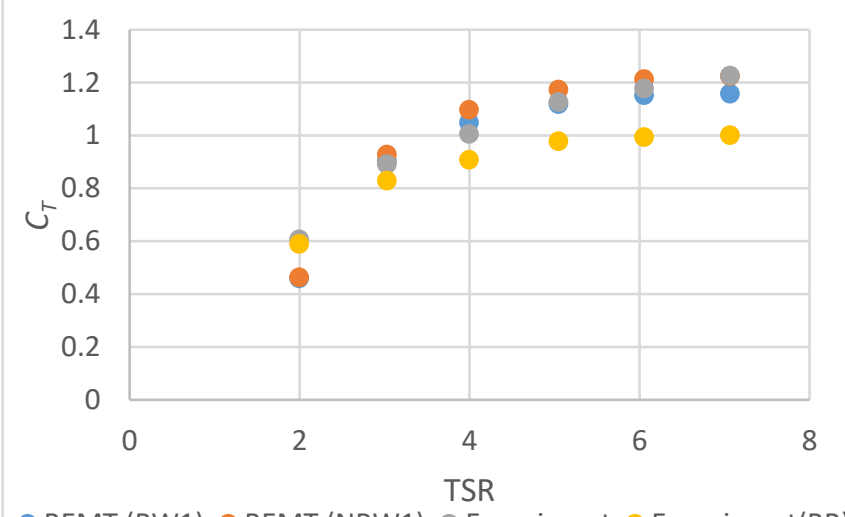

- BEMT (RW1) B BEMT (NRW1) Experiment Experiment(BR

Figure 12. С C $_{\mathrm{T}}$ comparison between BEMT calculations and experimental data for the inflow profiles with and without a turbine when the turbine operates under wave-current interactions with a wave height of approximately $0.19 \mathrm{~m}$ and an apparent wave period of $0.7 \mathrm{~s}$.

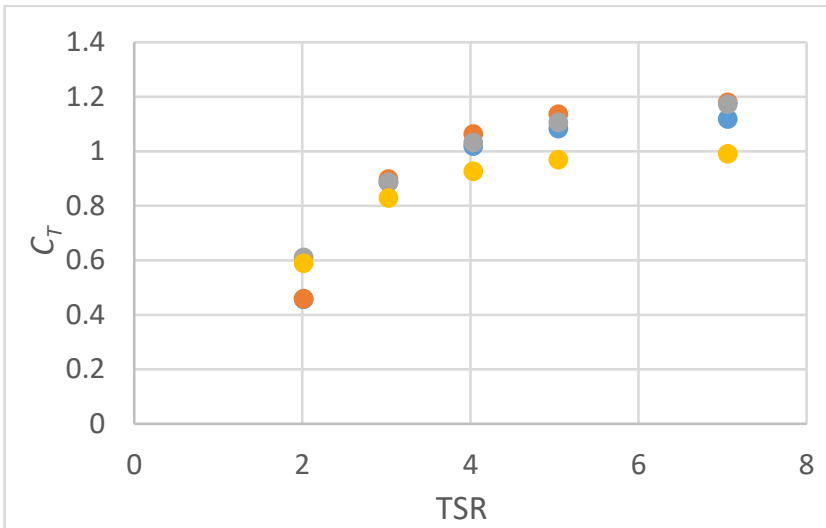

- BEMT (RW2) O BEMT (NRW2) Experiment Experiment(BR)

Figure 13. С $\mathrm{C}_{\mathrm{T}}$ comparison between BEMT calculations and experimental data for the inflow profiles with and without a turbine when the turbine operates under wave-current interactions with a wave height of approximately $0.09 \mathrm{~m}$ and an apparent wave period of $0.5 \mathrm{~s}$.

For experiments with a low TSR of 2, this gives higher $\mathrm{C}_{\mathrm{T}}$ values than predicted with BEMT. However, the differences between $C_{T}$ values from BEMT and experimental data increases in line with an increase in TSR. Applying blockage ratio correction to the experimental data results in a lower $C_{T}$ being predicted than the BEMT above TSR's of 3. These differences increase to approximate $16 \%$ and $24 \%$ for both wave conditions. The inflow profile with the turbine shows a slightly higher value than that without turbine at TSR 2 and 3, but the two profiles start to give similar values from TSR 4 to 7 .

The thrust and torque to calculate $C_{P}$ and $C_{T}$ values are shown in figure 14-17. 


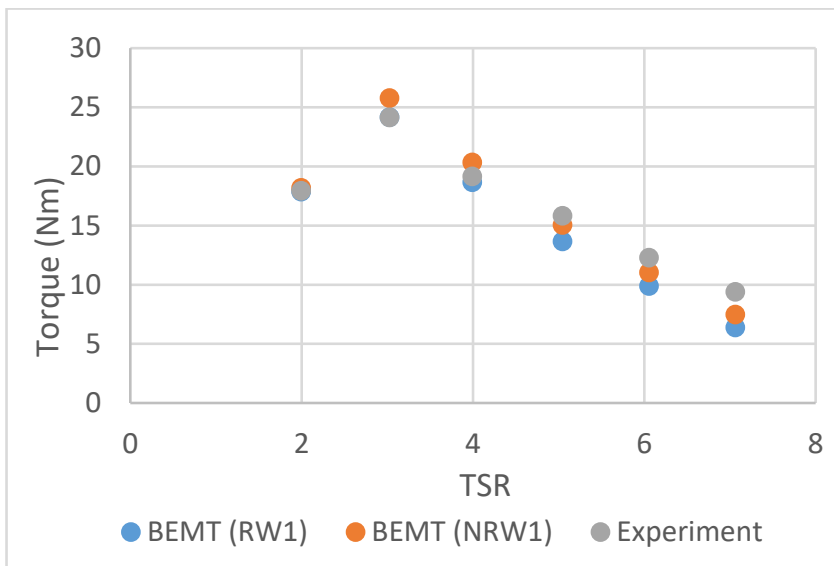

Figure 14. Torque comparison between BEMT calculations and experimental data for the inflow profiles with and without a turbine when the turbine operates under wave-current interactions with a wave height of approximately $0.19 \mathrm{~m}$ and an apparent wave period of $0.7 \mathrm{~s}$.

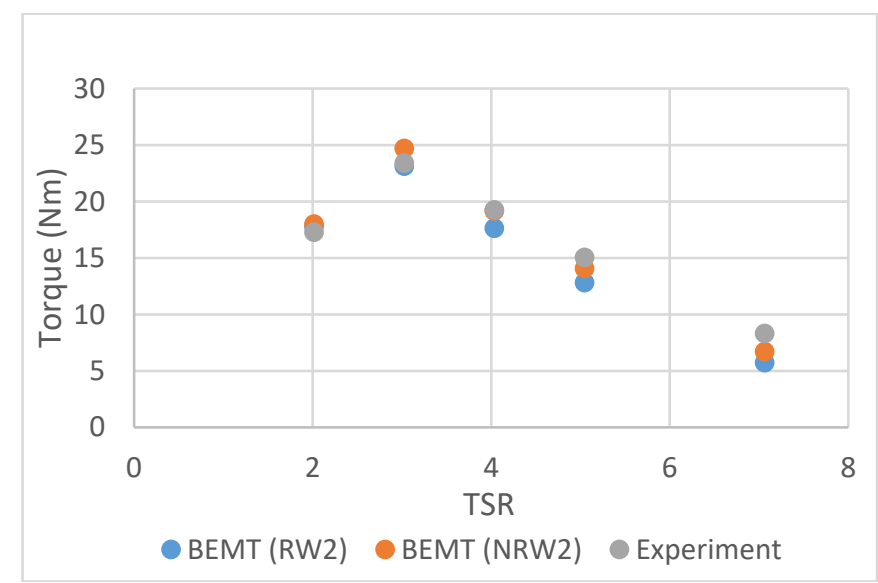

Figure 15. Torque comparisons between BEMT calculations and experimental data for the inflow profiles with and without a turbine when the turbine operates under wave-current interactions with a wave height of approximately $0.09 \mathrm{~m}$ and an apparent wave period of $0.5 \mathrm{~s}$.

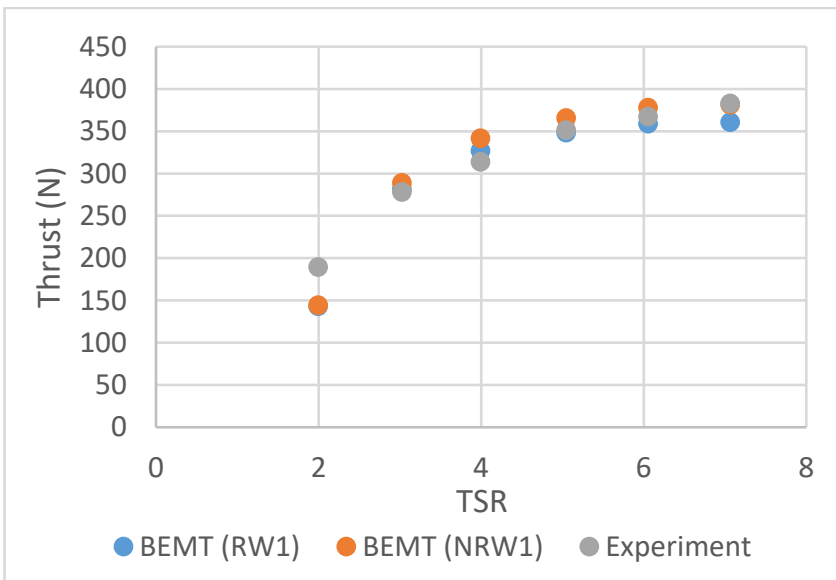

Figure 16. Thrust comparison between BEMT calculations and experimental data for inflow profiles with and without a turbine when the turbine operates under wave-current interactions with a wave height of approximately $0.19 \mathrm{~m}$ and an apparent wave period of $0.7 \mathrm{~s}$.

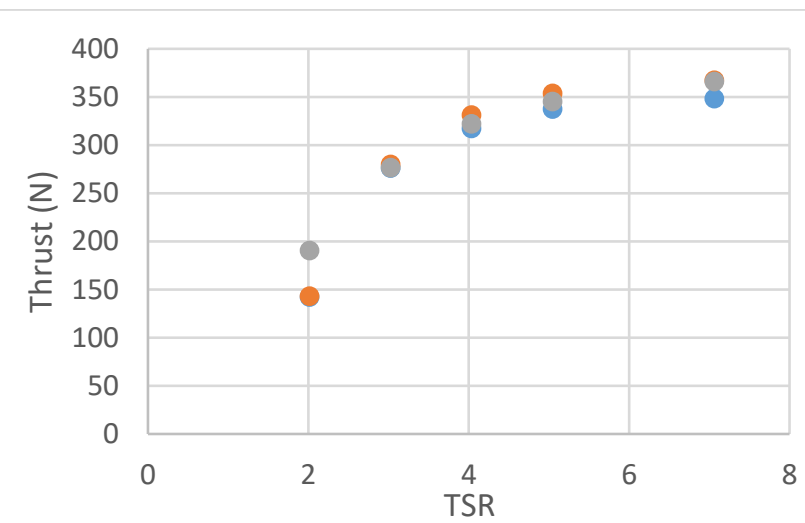

BEMT (RW2) BEMT (NRW2) Experiment

Figure 17. Thrust comparison between BEMT calculations and experimental data for inflow profiles with and without a turbine when the turbine operates under wave-current interactions with a wave height of approximately $0.09 \mathrm{~m}$ and an apparent wave period of $0.5 \mathrm{~s}$.

As shown in Figures 14-15, the Torque generated in both wave conditions at a TSR of 2 is approximately same. However, BEMT with the two inflow profiles begins to under predict the torque generated between TSR 5 to 7 . Generally, the BEMT model gives reasonable agreement with the Experimental data for the measured torque.

The Thrust results, as shown in Figure 16-17, for a lower TSR of 2 demonstrates that BEMT with two inflow profiles under-predicts thrust values for both wave conditions. Thrust begins to match the experimental data, with good agreement, as the TSR increases.

In both Torque and Thrust cases, the inflow profiles representative of flows without a turbine tend to obtain higher values than flows representative with turbine from TSR's 3 to 7. However, at TSR 2, the results generated from the two profiles are similar. It must be noted that the turbine operas under constant speed set by the motor controller, therefore, the passing wave will not change substantially the Reynolds numbers and hence, the lift and drag coefficients have not been modified for iterations. Subsequent work on this will assess the use of BEMT when looking at other control strategies proposed by [17] and [18]

\section{H. Discussion for non-uniform inflows}

As mentioned previously, the $C_{P}$ and $C_{T}$ derived in BEMT is calculated as:

$$
\begin{aligned}
& C_{P}=\frac{T \Omega}{0.5 \rho A V^{3}} \\
& C_{T}=\frac{F}{0.5 \rho A V^{2}}
\end{aligned}
$$

where $\mathrm{T}$ is torque on the rotor.

According to the loading result from Figure 14-17, the torque and thrust calculated by BEMT is in good agreement to that measured from the experiments. This indicates that the reason for the differences between the numerically and 
empirically derived $C_{P}$ and $C_{T}$ is heavily influenced by the characteristics of the inflow velocity, $\mathrm{V}$.

For a uniform current flow, the inflow velocity is constant and similar for each blade element section, and a consistent result can be obtained from the equations above. In the context of non-uniform flow conditions, the inflow velocity will be varying across each section of the blade element as the turbine operates as shown in Figure 2. Where experimental data is derived against a mean value to represent the inflow velocity this introduces inaccuracies within the calculations, as mentioned previously. Therefore, it is necessary to modify the method of $C_{P}$ and $\mathrm{C}_{\mathrm{T}}$ calculation to better represent the non-uniformity of the inflow conditions.

The new method being reported is based on a differential velocity observed across the rotor swept area, which is divided into several smaller areas, $\mathrm{Da}$, as shown in Figure 18.

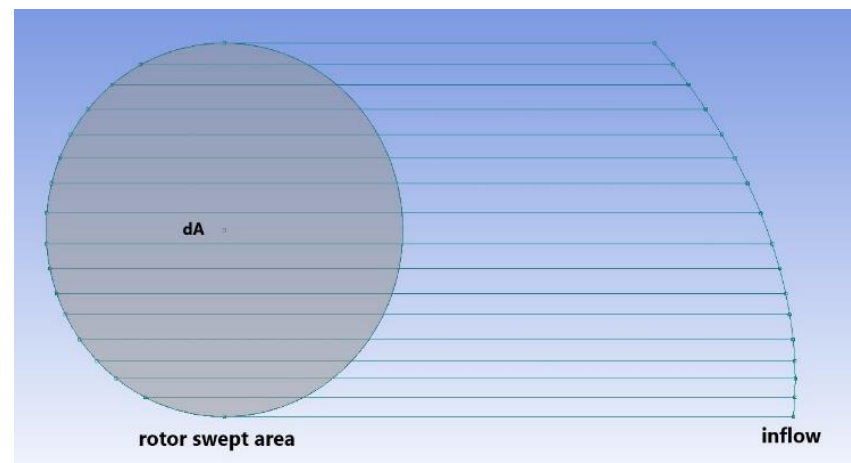

Figure 18. Schematic of the smaller area method

From the data analysis, the inflow profile is observed as a function of the water depth, $y$, where:

$$
V=f(y)
$$

and $\mathrm{dA}$ can be written as a function of $\mathrm{y}$, where

$$
d A=g(y)
$$

Therefore, a specific velocity value is applied for the inflow velocity at each smaller area $\mathrm{dA}$ section at the same depth. In doing this, the equations for $\mathrm{C}_{\mathrm{P}}$ and $\mathrm{C}_{\mathrm{T}}$ becomes

$$
\begin{aligned}
C_{P} & =\frac{T \Omega}{0.5 \rho \sum g(y) f(y)^{3}} \\
C_{T} & =\frac{F}{0.5 \rho \sum g(y) f(y)^{2}}
\end{aligned}
$$

This methodology is subsequently re-applied to the original experimental data and to BEMT.

\section{Non-uniform inflows with modifications}

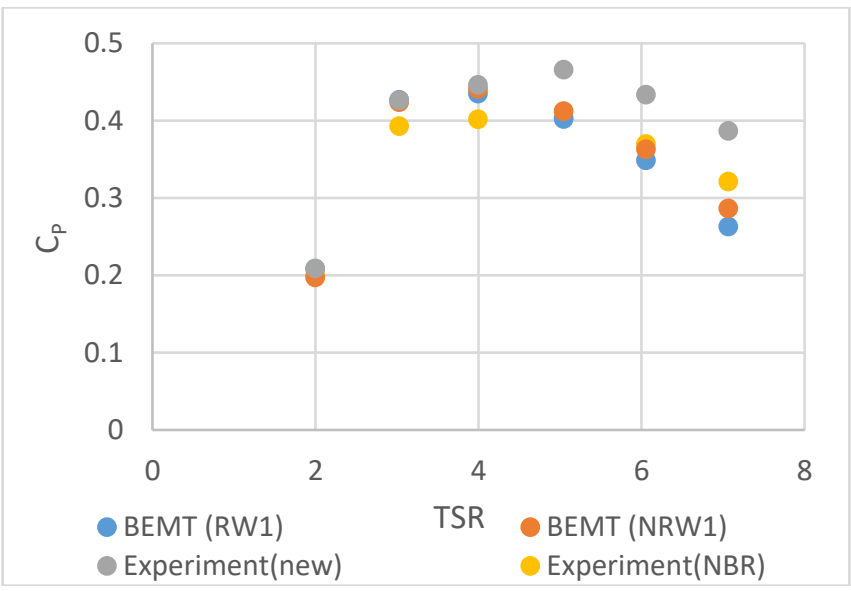

Figure 19. CP comparison between modified BEMT calculations and modified experimental data under wave-current interactions with a wave height of approximately $0.19 \mathrm{~m}$ and an apparent wave period of $0.7 \mathrm{~s}$.

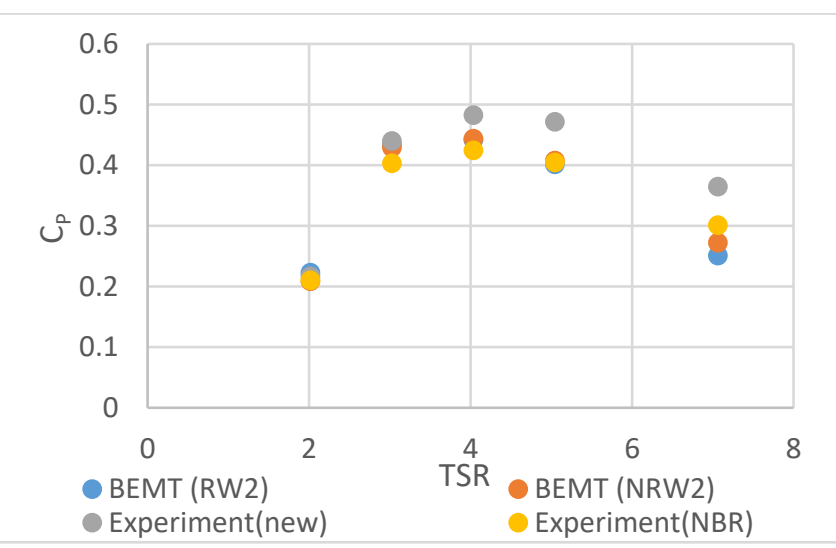

Figure 20. CP comparison between modified BEMT calculations and modified experimental data under wave-current interactions with a wave height of approximately $0.09 \mathrm{~m}$ and an apparent wave period of $0.5 \mathrm{~s}$.

Figures 19-20 show the comparisons of $C_{P}$ for the modified BEMT models, and empirical data calculated with the modified experimental velocity data. In the RW1 conditions, the BEMT results show a better agreement with the modified experimental data for TSR's 2 to 4, when compared with the original data sets for both inflow profiles. The modified experimental data increases in value when compared with the BEMT results for TSR's 5 to 7 . These differences increase to $31 \%$ and $26 \%$ for the inflow profiles representative of velocities experienced without a turbine, which is greater than the original comparison. However, the BEMT results present lower discrepancies with the modified experimental data with the introduction of blockage correction at TSR's 5 and 6. Generally, the modified BEMT models show an acceptable agreement with the modified experimental data with blockage correction applied for all TSR's. In the case of TSR 7, these differences peak at $18 \%$ and $11 \%$ for the different inflow velocity profiles, while these discrepancies parities are less than $9 \%$ for TSR's 2 to 6.

In RW2, the match between the modified experimental data including the application of a blockage ratio and the 
BEMT model shows an improvement when compared with the original comparison. The increased discrepancies only appear at TSR 7, where differences of $16 \%$ and $9 \%$ are established for profiles representative of an inflow velocities with and without a turbine. Over the remaining TSRs these differences are less than $8 \%$, with the smallest being $2 \%$ for inflow velocity profile representative without a turbine at TSR 5 .

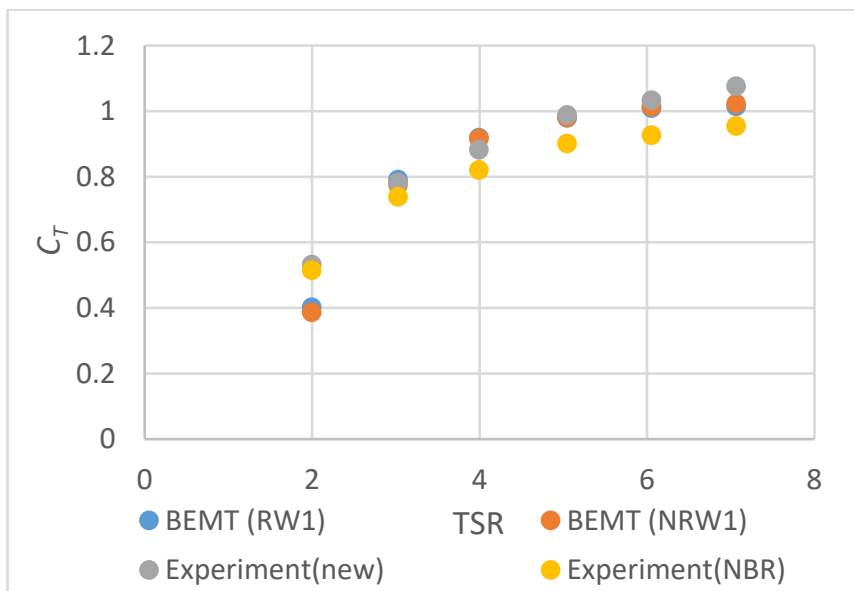

Figure 21. $\mathrm{C}_{\mathrm{T}}$ comparison between modified BEMT calculations and modified experimental data under wave-current interactions with a wave height of approximately $0.19 \mathrm{~m}$ and an apparent wave period of $0.7 \mathrm{~s}$.

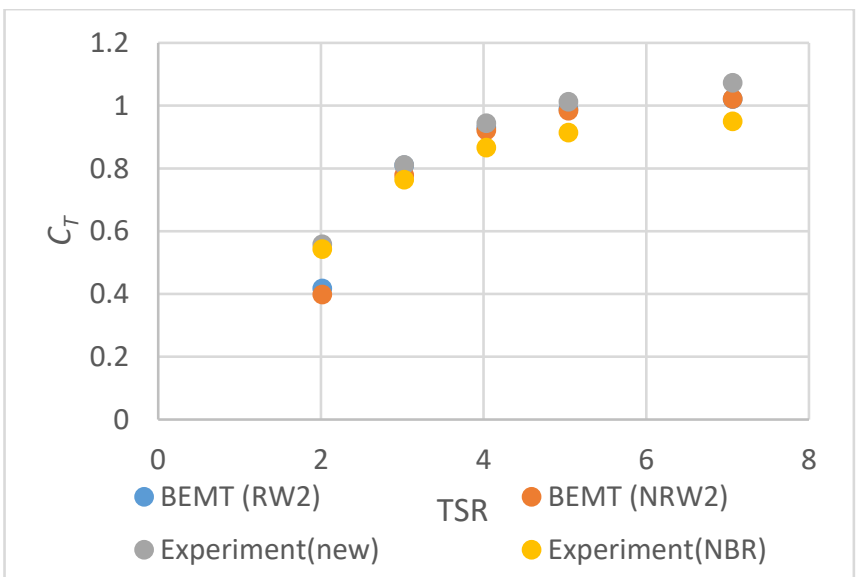

Figure 22. $\mathrm{C}_{\mathrm{T}}$ comparison between modified BEMT calculations and modified experimental data under wave-current interactions with a wave height of approximately $0.09 \mathrm{~m}$ and an apparent wave period of $0.5 \mathrm{~s}$.

Changes in the trend of $\mathrm{C}_{\mathrm{T}}$ comparison are negligible, with the highest $C_{\mathrm{T}}$ value from experimental data dropping from 1.2 to 1.08 and 1.07 for RW1 and RW2. Furthermore, the maximum discrepancies between experimental data with and without blockage correction applied decreases to $12 \%$ and $11 \%$ for both wave conditions. Within TSR ranges 3 to 7 , the highest discrepancy between the BEMT model and the experimental data with blockage correction is $7 \%$ for both inflow profiles in RW1 and $7.5 \%$ in RW2 conditions.

This paper outlines the use of BEMT to predict the performance of tidal stream turbines under wave and current conditions. Although some literature has been used to assess the impact of wave motion into tidal stream performance, no additional literature has been found by the authors which highlights the influence of non-uniforms flows into BEMT predictions.

\section{J. Blade stalls at low TSR}

According to the $\mathrm{Ct}$ and thrusts comparisons, it shows that BEMT underpredicted the thrust at low TSR around 2, it is expected that the blades are stalling in BEMT simulation, so that there are losses of lift forces of blades. Table IV shows the average angles of attack (AoA) for the 20 elements on the blade in BEMT simulation to confirm whether the stall happened.

TABLE IV

ANGLE OF ATTACK FOR ELEMENTS ON BLADE AT TSR 2

\begin{tabular}{|c|c|c|c|c|c|}
\hline $\begin{array}{l}\text { Element } \\
\text { number }\end{array}$ & $\begin{array}{c}\text { Blade } \\
\text { stall } \\
\text { AoA } \\
\text { (deg) }\end{array}$ & $\begin{array}{c}\text { AoA in } \\
\text { RW1 } \\
\text { (deg) }\end{array}$ & $\begin{array}{c}\text { AoA in } \\
\text { NRW1 } \\
\text { (deg) }\end{array}$ & $\begin{array}{c}\text { AoA in } \\
\text { RW2 } \\
\text { (deg) }\end{array}$ & $\begin{array}{c}\text { AoA in } \\
\text { NRW2 } \\
\text { (deg) }\end{array}$ \\
\hline 1 & \multirow{20}{*}{16} & 40.18 & 40.67 & 39.66 & 40.26 \\
\hline 2 & & 36.77 & 37.32 & 36.13 & 36.84 \\
\hline 3 & & 34.26 & 34.85 & 33.51 & 34.32 \\
\hline 4 & & 32.39 & 33.00 & 31.54 & 32.43 \\
\hline 5 & & 30.91 & 31.52 & 29.99 & 30.93 \\
\hline 6 & & 29.65 & 30.25 & 28.68 & 29.65 \\
\hline 7 & & 28.48 & 29.04 & 27.48 & 28.46 \\
\hline 8 & & 27.31 & 27.84 & 26.31 & 27.28 \\
\hline 9 & & 26.10 & 26.60 & 25.12 & 26.08 \\
\hline 10 & & 24.85 & 25.33 & 23.92 & 24.85 \\
\hline 11 & & 23.58 & 24.03 & 22.72 & 23.60 \\
\hline 12 & & 22.30 & 22.75 & 21.54 & 22.37 \\
\hline 13 & & 21.05 & 21.52 & 20.42 & 21.19 \\
\hline 14 & & 19.83 & 20.35 & 19.35 & 20.08 \\
\hline 15 & & 18.63 & 19.22 & 18.32 & 19.00 \\
\hline 16 & & 17.38 & 18.07 & 17.24 & 17.89 \\
\hline 17 & & 15.94 & 16.75 & 15.96 & 16.55 \\
\hline 18 & & 14.05 & 14.99 & 14.27 & 14.83 \\
\hline 19 & & 10.86 & 11.82 & 11.41 & 11.79 \\
\hline 20 & & 5.53 & 6.20 & 6.07 & 6.23 \\
\hline
\end{tabular}

As shown int Table IV, most of the elements AoAs are larger than the stall AoA of blade at TSR 2, this is the reason why the thrusts on the blades obtained form BEMT are lower than the experiment.

\section{CONCLUSIONS AND FUTURE WORK}

Comparisons between BEMT and a variety of experimental testing campaigns were undertaken in this paper. Two uniform flow conditions of 0.5 and $1.0 \mathrm{~m} / \mathrm{s}$ were used in combinations with two wave heights and periods. It was found that poor agreement was achieved for both power and thrust mean values when comparing the $0.5 \mathrm{~m} / \mathrm{s}$ cases. One reason for this may be that the turbine was not able to generate enough power due to drive train friction losses at such low flow velocities and thus the model was not able to predict these conditions. The same may be applicable to thrust. Another reason may be related to the sensitivity of the instrumentation used to quantify the axial 
loading developed by the turbine at low flow velocities. Future work will contemplate the use of additional instrumentation when undertaking experimental works related to wave-current interactions to further verify the modified BEMT model.

Good agreement was obtained between the model and the experimental data for flow velocities of $1.0 \mathrm{~m} / \mathrm{s}$ cases. An approximate discrepancy observed in the average values of $\mathrm{C}_{\mathrm{P}}$ for the experimental and the BEMT data was of approximately $3 \%$.

Two wave conditions with non-uniform flow have been investigated. This revealed that the method of calculating the power and thrust coefficient from experimental data requires to be modified when the turbine operates in nonuniform flow fields. The blockage effect has a significant impact on empirical data derived from flume testing and required the development of a blockage ratio correction for non-uniform flow test. The presence of the turbine has an effect on the velocity inflow profile, therefore an inflow profile representative of the flume without a turbine should be selected as the input data for the modified BEMT model.

The modified BEMT model using an inflow velocity profile without a turbine shows good agreement with the modified experimental data with blockage correction for derivation of the power coefficient, especially for the RW2 condition. The mean difference observed in $C_{P}$ for BEMT and modified experimental data with blockage ratio correction was $5.6 \%$, with a maximum discrepancy of $10.8 \%$ in RW1 conditions. It is shown that the average difference in $C_{P}$ for RW2 conditions was $4.4 \%$. It is found that poor agreement was attained at a low TSR of 2 or less in $\mathrm{C}_{\mathrm{T}}$ comparison because the blade is stalling in BEMT simulation, but disparities between BEMT and modified experimental data with blockage ratio correction for all other TSRs was less than $8 \%$.

Within future work, it may be necessary to increase the inflow profile data points obtained from experimental flow characterisation so that the resolution of the velocity function will be improved to give a higher accuracy. The thrust loading obtained from the BEMT model in low TSRs is planned to be investigated further. Finally, enhanced blockage correction methods should be investigated to find out which is the most appropriate one for higher blockage ratios and greater non-uniformity in experimental flow conditions.

\section{References}

[1] Marine Energy, "Marine Energy," 2704 2018. [Online]. Available: https://marineenergy.biz/2018/04/27/atlantisto-study-japanese-tidal-stream/.

[2] Marine Energy, "Marine Energy,” 2704 2018. [Online]. Available:

https://marineenergy.biz/2018/04/27/seabased-makes-srilanka-wave-energy-deal/.
[3] T. Nevalainen, C. Johnstone and A. Grant, "A sensitivity analysis on tidal stream turbine loads caused by operational, geometric design and inflow parameters," International Journal of Marine Energy, vol. 16, pp. 5164, 2016.

[4] S. Tatum, C. Frost, M. Allmark, D. O’Doherty, A. Mason-Jones, P. Prickett, R. Grosvenor, C. Byrne and T. O'Doherty, "Wave-current interaction effects on tidal stream turbine performance and loading characteristics," International Journal of Marine Energy, 2015.

[5] N. Barltrop, K. Varyani, A. Grant, D. Clelland and X. Pham, "Investigation into wave-current interactions in marine current turbines," Proc. IMechE Part A: Journal of Power and Energy, vol. 221, 2007.

[6] S. Ordonez-Sanchez, K. Porter, C. Frost, M. Allmark, C. Johnstone and T. O'Doherty, "Effects of Wave-Current Interactions on the Performance of Tidal Stream Turbines," Singapore, 2016.

[7] B. Gaurier, P. Davies, A. Deuff and G. Germain, "Flume tank characterization of marine current turbine blade behaviour under current and wave loading," Renewable Energy, pp. 1-12, 2013.

[8] T. d. J. Henriques, S. Tedds, A. Botsari, G. Najafian, T. Hedges, C. Sutcliffe, I. Owen and R. Poole, "The effects of wave-current interaction on the performance of a model horizontal axis tidal turbine," International Journal of Marine Energy, 8, pp. 17-35, 2014.

[9] Department of Aerospace Engineering, University of Illinois, "UIUC Applied Arodynamics Group," 2018. [Online]. Available: http://mselig.ae.illinois.edu/index.html.

[10] S. Ordonez-Sanchez, R. Ellis, K. E. Porter, M. Allmark, T. O’Doherty, A. Mason-Jones and C. Johnstone, "Numerical Models to Predict the Performance of Tidal Stream Turbines Working under Off-Design Conditions," Proceedings of the Royal Society A (under review).

[11] J. M. L. Buhl, "New Empirical Relationship between Thrust Coefficient and Induction Factor for the Turbulent Windmill State," National Renewable Energy Lab, 2005.

[12] A. Mason-Jones, "Performance assessment of a Horizontal Axis Tidal Turbine in a high velocity shear," Cardiff University, School of Engineering, Centre for Research in Energy Waste and the Environment, Cardiff, 2013.

[13] C. Boake, A. Lidderdale, J. Lawrence, F. Salvatore, G. Germain, G. Colicchio and B. Jacob, "Marinet D2.7 Tidal Measurement Best Practice Manual," Marine Renewables Infrastructure Network, 2013.

[14] M. J. Allmark, "Condition Monitoring and Fault Diagnosis of Tidal Stream Turbines Subjected to Rotor Imbalance Faults," Ph.D. dissertation,: Cardiff Marine Energy Research Group, Cardiff University, Cardiff, UK, 2017. [Online]. Available http://orca.cf.ac.uk/98633/

[15] K. E. Porter, S. E. Ordonez-Sanchez, R. E. Murray, M. Allmark, C. M. Johnstone, T. O'Doherty, D. A. Doman and P. Michael J Pegg, "Flume Testing of Passively Adaptive Composite Tidal Turbine Blades under Combined Wave and Current Loading," Journal of Fluid and Structures, vol. 93, 2020. 
[16] A. S. Bahaj, A. F. Molland, J. R. Chaplin and W. M. J. Batten, "Power and thrust measurements of marine current turbines under various hydrodynamic flow conditions in a cavitation tunnel and a towing tank.," Renewable energy, vol. 32, no. 3, pp. 406-426, 2007.

[17] R. Martinez, S. Ordonez-Sanchez, M. Allmark, C. Lloyd, T. O'Doherty, B. Gaurier, G. Germain and C. Johnstone, "Analysis of the effects of control strategies and wave climates on the loading and performance of a laboratory scale horizontal axis tidal turbine," Ocean Engeering, vol. 212, no. 107713, 2020.

[18] S. Ordonez-Sanchez, M. Allmark, K. Porter, R. Ellis, C. Lloyd, I. Santic, T. O'Doherty and C. Johnstone, "Analysis of a horizontal-axis tidal turbine performance in the presence of regular and irregular waves using two control strategies," Energies, vol. 12, no. 3, 2019.

[19] Tidal Energy Today, "Scotrenewables hits $1 \mathrm{GWh}$ tidal generation mark," 29 November 2017. [Online]. Available: https://tidalenergytoday.com/2017/11/29/scotrenewableshits-1gwh-tidal-generation-mark/.
[20] B. Sellar, "Redapt,” 201705 01. [Online]. Available: http://redapt.eng.ed.ac.uk/index.php.

[21] Tidal Energy Today, "MeyGen claims world's first as it welcomes final AHH turbine," 3108 2017. [Online]. Available: https://tidalenergytoday.com/2017/08/31/meygen-claimsworld-first-record-final-ahh-turbine/.

[22] B. G. Sellar and D. R. Sutherland, "Technical Report on Tidal Site Characterisation During the ReDAPT Project " Tidal Energy Site Characterisation at the Fall of Warness, EMEC, UK"," The University of Edinburgh, Edinburgh, 2016.

[23] M. S. Selig, J. J. Guglielmo, A. P. Broeren and P. Giguere, "Summary of Low-Speed Airfoil Data," Department of Aeronautical and Astronautical Engineering, University of Illinois, Urbana Champaign, 1995.

[24] J. Thomson, B. Polagye, V. Durgesh and M. Richmond, "Measurements of turbulence at two tidal energy sites in Puget Sound, WA," IEEE Journal of Oceanic Engineering, vol. 37, pp. 363-374, 2012. 